\title{
Comparative study on Insulin-Like Growth Factor I (IGF-I) plasma concentrations in new-born horse foals, donkey foals and calves
}

\author{
Panzani $\mathrm{S}^{1}$, Carluccio $\mathrm{A}^{2}$, Faustini $\mathrm{M}^{1}$, Prandi $\mathrm{A}^{3}$, Probo $\mathrm{M}^{1}$, and Veronesi MC ${ }^{1 *}$ \\ ${ }^{1}$ Department of Veterinary Medicine, Università degli Studi di Milano, Milan, Italy \\ ${ }^{2}$ Faculty of Veterinary Medicine, Università degli Studi di Teramo, Teramo, Italy \\ ${ }^{3}$ Department of Agricultural, Food, Environmental and Animal Sciences, University of Udine, Udine, Italy
}

\begin{abstract}
During the postnatal period, the most important growth regulator is represented by the insulin-like growth factor-I (IGF-I). Horses, donkeys, and cattle are monotocous species with considerable gestational lengths. The birth of a live, viable newborn at the end of a healthy pregnancy, and the survival of the single newborn, represent essential prerequisites for a successful reproductive success. Therefore, the full knowledge about neonatal biology of these species is mandatory. The aim of this study was to investigate the IGF-I plasma profiles in the neonates of these three species during the first 14 days of life. Six horse foals, 6 donkey foals and 6 calves, healthy and mature, were enrolled, and blood samples collected at 30 minutes, 3, 12, 24 hours, and 3, 7, 10, 14 days after birth. IGF-I plasma concentrations were analysed by RIA. Horse foals showed higher ( $\mathrm{p}<0.05)$ IGF-I plasma concentrations at 10 and 14 days of age in comparison to the values observed at 24 hours of age, while higher $(\mathrm{p}<0.05)$ IGF-I plasma concentrations were detected at 14 days of age in comparison to all the previous sampling times. Donkey foals showed a significantly higher $(\mathrm{p}<0.05)$ value at 10 days compared to the first 24 hours. Calves showed the highest value at 30 minutes, followed by a significant ( $<<0.05$ ) decrease at 3 hours and a further significant $(p<0.05)$ decrease at 7 days of age. Comparing the profiles of the three species, no differences between horse and donkey foals were observed, while calves showed significant $(p<0.05)$ lower levels compared to donkeys at 7,10 and 14 days and to horse foals at 14 days. This study confirm the important role of IGF-I in the early postnatal life in these three species, but also underlines the need of additional species-specific studies for a better understanding of the possible different role played by IGF-I in the different species neonatal physiology.
\end{abstract}

\section{Introduction}

Starting from the last stage of pregnancy and especially during the early neonatal phase, the new born should provide multiple adjustments to adapt to the extra uterine life. Among several physiological changes, the endocrine system, considered functional already at birth, should continue its maturation during the early neonatal life [1-4]. Several hormones and growth factors interact and work synergically to allow a correct somatic growth and development, under the regulation of the hypothalamic-pituitary axis [2,5,6]. During the fetal and neonatal growth, Insulin-Like Growth Factors (IGF) play a central role as growth regulators [7-11]. Even if, before birth, fetal growth and development are mainly regulated by IGF-II [12], during the postnatal period the most important growth regulator is represented by the IGF-I [13].

The free circulating IGF-I mediates several actions of the pituitary Growth Hormone (GH); GH, in turn, regulates the hepatic and local production and release of IGF-I [14,15]. GH and IGF-I affect cell growth in all systems [15], but, above all, they regulate the musculoskeletal growth. The somatotropic axis and IGFs are also involved in the GastroIntestinal Tract (GIT) development, and especially in the proliferation and maturation ofenterocytes as demonstrated in newborn calves [16-18].

In human and veterinary medicine, IGF-I has been deeply investigated, but not so many studies focused on their role in the early neonatal life, which still remain an interesting stage of study in almost all species, despite some researchers investigated the IGF-I profiles in some animal species new-borns [3,19-22].Because the horse, the donkey, and the bovine are monotocous species with considerable gestational lengths, the birth of a live and viable newborn at the physiological end of a healthy pregnancy, and the survival of the neonates, represent essential prerequisites for a successful reproductive process.

To date, most of the investigations in veterinary neonatology were performed in the horse foal, while few studies have been conducted, for example, on the neonatal physiology in the donkey. As well, despite the huge literature about adult cattle, also several aspects of the calf physiology remain to be clarified. In fact, the interest for horse foals increased already in the 80 's, when several researches started to focus not only on neonatal physiology, but also on neonatal diseases. The rationale of this interest was based on the economic value of many horse foals and the deep impact of the neonatal intensive care expense [23]. However, although progresses in leaps and bound were made, several questions remained without an answer, and the full knowledge about neonatal biology is still a goal for the equine veterinarian. In the donkey, instead, the scientific interest increases only in the last years. In

Correspondence to: Veronesi Maria Cristina, Associate Professor, Clinical Veterinary Surgery and Obstetrics, Department of Veterinary Medicine, Italy, Tel: 02503 18149; E-mail:maria.veronesi@unimi.it

Key words: horse foal, donkey foal, calf, IGF-I, newborn

Received: February 17, 2017; Accepted: March 07, 2017; Published: March 10, 2017 
fact, after a time in which the global population of donkeys was going to disappear, the interest for this species renewed, because of new possible fields of usefulness, such as the production of hypoallergenic milk, and the so-called onotherapy. In Italy, all the donkey breeds were declared endangered, and projects for population preservation developed; among the endangered donkey breeds, the Martina Franca breed was included. According to those programs of population preservation, several research projects were performed to improve knowledge on reproductive physiology and to optimize the process of repopulation [24-27]. The survival of each new born donkey foal is therefore essential for a successful reproductive process and population improvement. For this reason, the full knowledge about donkey foal physiology is mandatory also in this species. From a scientific point of view, until recently, the donkey was often considered just a "smaller horse" and, because both species belong to the same genus Equus, it was considered similar to the horse for anatomic and physiologic features. However, some studies have already demonstrated that some characteristics are unique, and specific for this species [24-26].

In both horse and donkey newborn foals, the early process of somatic growth is pivotal and regulated by several factors, including also the IGF system. In calves, the first two postnatal weeks are characterized by high morbidity and mortality rates [28], with consistent economic impact. Diseases, especially of the Gastrointestinal Tract (GIT), such as severe diarrhoea, are frequently followed by fatal systemic diseases. Adaptations of the GIT and of its functions are critical, due to the change from parenteral nutrition to exclusively enteral nutrition. Insufficient morphological and functional adaptations of the GIT are considered to be of central etiological importance for diseases [29]. A better knowledge of factors mediating postnatal growth and development of the gastrointestinal tract is essential to understand how to improve digestive efficiency, health status, well-being and growth performance, and contemporary reduce postnatal morbidity and mortality of neonates. Because of the possible role of IGF-I in the process of intestinal development, the investigation of its profile in the newborn calf deserves scientific interests.

For all the above mentioned reasons, the present study was aimed to evaluate the IGF-I plasma profile in at term, mature and viable new born horse foals, donkey foals and calves during the first two weeks of life, in the purpose to improve the neonatal biology knowledge in these species. Furthermore, a comparison among the IGF-1 neonatal profile among the three species was also performed.

\section{Materials and methods}

\section{Equine}

The study was approved by the Interuniversity Ethics Committee for Animal Experimentation (CEISA, Protocol n. \#45/2013/CEISA/ $\mathrm{COM})$.

Six Standardbred horse foals and six Martina Franca foals, delivered by spontaneous, unassisted, vaginal parturition from multiparous mares and jennies, were enrolled. For each mare and jenny some clinical data were recorded: gestational length, fetal and placenta expulsion times [30].The following characteristics were also evaluated for each newborn horse and donkey foal: the Apgar index within 10 minutes of birth, the presence of suck and righting reflexes, and the Times to Stand Up (TSU) and to The First Suck (TFS). According to the modified Apgar score index used, a score of 2, 1, or 0 was assigned regarding the heart rate and rhythm, the respiratory rhythm, the body tone, the colour of mucous membranes, and the response to stimuli. An Apgar index $\geq 7$ was considered normal [26]. Some physical and behavioural characteristics were evaluated to assess foal maturity, such as birth weight, body size, hair coat, head shape, ear position, and absence of periarticular laxity [31-33].

\section{Bovine}

Six Holstein-Friesian calves were enrolled, delivered by spontaneous, unassisted, vaginal parturition from second-third parity cows. For each cow data about gestation length, fetal and placental expulsion times were recorded. In order to assess calf viability, the interval between birth and Sternal Recumbency (TSR) [34] and TSU were evaluated. For each calf, a modified Apgar score was measured within 10 min of birth; an Apgar index $\geq 7$ was considered normal [26]. Birth weight and maturity (prematurity defined as presence of low birth weight, incomplete eruption of incisor teeth, short and silky hair coat) were also recorded [35]. Each calf, immediately after birth, was transferred to a single box until the age of 14 days and fed with colostrum obtained from the colostrum bank of the herd. From day 3 after birth, calves were fed twice a day with pasteurized herd milk, in quantity of $10 \%$ of their body weight.

\section{Sampling collection}

From each foal and calf, blood samples were collected from the jugular vein into heparinized tubes, according to the following sampling schedule: 30 minutes after parturition (and always before first colostrum intake); 3, 12, 24 hours after birth, and 3, 7, 10, 14 days of age. After collection, samples were centrifuged at $1000 \mathrm{x}$ g for 20 minutes and the resulting plasma was stored at $-20^{\circ} \mathrm{C}$ until analysis.

\section{IGF-I analysis}

IGF-I plasma levels were evaluated using a modified RIA technique [36]. In this method, a cryoprecipitation step was used to eliminate aggregated IGF binding proteins in plasma extracts. Briefly, after acidethanol extraction ( $87.5 \%$ ethanol and $12.5 \% \mathrm{HCl} 2 \mathrm{M}$, v:v), an aliquot of the supernatant was neutralized with $0.855 \mathrm{M}$ Tris base at a ratio of 5:2. The samples were then stored at $-20^{\circ} \mathrm{C}$ for 1 hour and immediately centrifuged at $3000 \mathrm{x} \mathrm{g}$ for $30 \mathrm{~min}$ at $4^{\circ} \mathrm{C}$. After centrifugation, the supernatant fluid was diluted in assay buffer $(\mathrm{NaH} 2 \mathrm{PO} 4,0.6 \mathrm{~mol} /$ liter; EDTA, 3.72 g/litre; protaminsulfate, 200 mg/litres; Tween 20, 500 $\mu \mathrm{l} /$ litre; $\mathrm{NaN}_{3}, 200 \mathrm{mg} /$ litres; $\mathrm{pH}$ 7.5) (final dilution of plasma: 1/28). The diluted extracts were measured by RIA method using ${ }^{125} \mathrm{I}$-labeled human IGF-I $(9,000 \mathrm{cpm}$; specific activity: $50 \mu \mathrm{Ci} / \mu \mathrm{g})$ and a rabbit antiserum (1/80,000 final dilution) rose against recombinant human IGF-I. (NovozymesBiopharma; Thebarton, SA 5031, Australia). Recombinant human IGF-I (rhIGF-I, Roche S.p.A, Italy) was used for iodination as tracer and as standard in the radioimmunoassay. The tracer was prepared with $\mathrm{Na}^{125} \mathrm{I}$ by the iodogen method [37]. Following incubation for $24 \mathrm{~h}$, antibody-bound hormone was precipitated with goat antirabbit gamma globulin. The sensitivity of the assay, calculated as the interpolated dose of the response to a concentration of zero minus the statistical error, was $1.8 \mathrm{ng} / \mathrm{ml}$. Intra and inter-assay coefficients of variation were 8.5 and $12.7 \%$, respectively.

\section{Statistical analysis}

Plasma IGF-I changes, within each group, along the time of study, were analysed by one-way ANOVA test, followed by the Tukey test for multiple comparisons. A one-way ANOVA test was used to analyse possible IGF-I differences in every sampling time, among the three 
groups. Significance was set for $\mathrm{p}<0.05$.

\section{Results}

\section{Clinical findings}

All the mares, jennies and cows had a normal course of pregnancy and all the singleton deliveries complied with the criteria for normal, spontaneous, vaginal, parturition; thus, all the 18 females and their newborns were included in the study. In Table 1, data about pregnancy length, fetal and placental expulsion time, in the studied mares, jennies and cows, are reported. In Table 2, data about neonatal clinical features in the studied horse and donkey foals, as well as in newborn calves, are reported.

\section{IGF-I profiles and comparison among groups}

Data regarding plasma IGF-I concentrations during the first two weeks of age in the 6 horse foals, the 6 donkey foals and the 6 calves included in this studyare reported in Table 3. Figure 1 shows the three different profiles of IGF-1 plasma concentrations in the 6 horse foals, in the 6 donkey foals and in the 6 calves included in this study during the first 2 weeks of age. In the horse foals, no significant differences were found between each sampling time in the time frame between 30 minutes and 7 days after birth, although an apparent trend of IGF-I plasma concentrations increasing was seen (Figure 1). Significantly $(\mathrm{p}<0.05)$ higher IGF-I plasma concentrations were found at 10 days of age in comparison to the values observed at 24 hours of age, while higher $(\mathrm{p}<0.05)$ IGF-I plasma concentrations were detected at 14 days of age in comparison to all the previous sampling times (Table 3 ).

Also in donkey foals, despite the apparent IGF-I plasma concentrations increasing trend (Table 3, Figure 1), no statistical

Table 1. Pregnancy length, fetal and placental expulsion time (mean \pm SD) in the 6 mares, the 6 jennies and the 6 cows included in this study

\begin{tabular}{|c|c|c|c|}
\hline & $\begin{array}{c}\text { Pregnancy length } \\
\text { (days) }\end{array}$ & $\begin{array}{c}\text { Fetal expulsion time } \\
\text { (min) }\end{array}$ & Placental expulsion time \\
\hline Mares & $336.4 \pm 11$ & $25 \pm 4.1$ & $15.2 \pm 10.7 \mathrm{~min}$ \\
\hline Jennies & $362.5 \pm 12.7$ & $16.2 \pm 7.0$ & $68.8 \pm 54.4 \mathrm{~min}$ \\
\hline Cows & $281 \pm 4.3$ & $36.8 \pm 33.6$ & Always $<24 \mathrm{~h}$ \\
\hline
\end{tabular}

Table 2. Clinical data (mean \pm SD) for the 6 horse foals, the 6 donkey foals and the 6 calves included in this study

\begin{tabular}{|c|c|c|c|c|c|c|}
\hline & $\begin{array}{c}\text { Sex } \\
(\mathrm{M} / \mathrm{F})\end{array}$ & $\begin{array}{c}\text { Birth weight } \\
(\mathrm{Kg})\end{array}$ & $\begin{array}{c}\text { TSR } \\
(\mathrm{min})\end{array}$ & $\begin{array}{c}\text { TSU } \\
(\mathrm{min})\end{array}$ & $\begin{array}{c}\text { TFS } \\
(\mathrm{min})\end{array}$ & APGAR \\
\hline Horse foals & $2 / 4$ & $42.2 \pm 5.3$ & - & $55 \pm 42.4$ & $77.5 \pm 26.6$ & $9.8 \pm 0.4$ \\
\hline Donkey foals & $3 / 3$ & $29.0 \pm 4.9$ & - & $60.8 \pm 12.9$ & $119.5 \pm 38.1$ & $8.7 \pm 0.8$ \\
\hline Calves & $3 / 3$ & $35.0 \pm 5.4$ & $6.7 \pm 3.5$ & $37.2 \pm 15.4$ & - & $9 \pm 1.2$ \\
\hline
\end{tabular}

Table 3. IGF-I plasma concentrations (mean \pm SD) in the 6 horse foals, 6 donkey foals and 6 calves during the first 2 weeks of age

\begin{tabular}{|c|c|c|c|}
\hline \multirow{2}{*}{ Time after birth } & \multicolumn{3}{|c|}{ IGF-I $(\mathrm{ng} / \mathrm{ml})$} \\
\cline { 2 - 4 } & Horse foals & Donkey foals & Calves \\
\hline 30 min & $40.4 \pm 24.8^{\mathrm{BC}}$ & $37.8 \pm 32.3^{\mathrm{B}}$ & $59.9 \pm 13.0^{\mathrm{A}}$ \\
\hline 3 hours & $45.6 \pm 29.9^{\mathrm{BC}}$ & $30.0 \pm 22.4^{\mathrm{B}}$ & $39.3 \pm 10.6^{\mathrm{B}}$ \\
\hline 12 hours & $48.3 \pm 23.9^{\mathrm{BC}}$ & $33.1 \pm 26.0^{\mathrm{B}}$ & $26.8 \pm 6.7^{\mathrm{B}}$ \\
\hline 24 hours & $41.0 \pm 21.1^{\mathrm{C}}$ & $37.6 \pm 28.7^{\mathrm{B}}$ & $14.9 \pm 7.4^{\mathrm{B}}$ \\
\hline 3 days & $47.7 \pm 15.2^{\mathrm{BC}}$ & $88.2 \pm 100.9^{\mathrm{AB}}$ & $23.8 \pm 5.2^{\mathrm{BC}}$ \\
\hline 7 days & $61.7 \pm 29.2^{\mathrm{ab}, \mathrm{BC}}$ & $172.0 \pm 173.2^{\mathrm{a}, \mathrm{AB}}$ & $5.1 \pm 2.5^{\mathrm{b}, \mathrm{C}}$ \\
\hline 10 days & $82.0 \pm 18.2^{\mathrm{ab}, \mathrm{B}}$ & $254.2 \pm 199.8^{\mathrm{a}, \mathrm{A}}$ & $7.9 \pm 2.4^{\mathrm{b}, \mathrm{C}}$ \\
\hline 14 days & $139.0 \pm 19.7^{\mathrm{a}, \mathrm{A}}$ & $233.4 \pm 135.6^{\mathrm{a}, \mathrm{AB}}$ & $4.6 \pm 2.9^{\mathrm{b}, \mathrm{C}}$ \\
\hline
\end{tabular}

a,b denote significant differences within row with $\mathrm{p}<0.05$;

A,B,C denote significant differences within columns with $\mathrm{p}<0.05$ differences were found between 30 minutes and 7 days after birth. Significant $(\mathrm{p}<0.05)$ IGF-I plasma concentrations increase was observed at 10 days of age in comparison to the time frame ranging between 30 minutes and 24 hours of age (Table 3 ).

In the newborn calves, instead, a decreasing trend (Table 3, Figure 1) of IGF-I plasma concentrations was observed, with significantly $(p<0.05)$ higher values at 30 minutes after birth as compared to all the following sampling times. A further significant $(\mathrm{p}<0.05)$ decrease was observed in the time frame ranging between 7 and 14 days of age, as compared to the first 24 hours after birth (Table 3). When the IGF-I plasma concentrations in each sampling time among horse foals, donkey foals and calves were compared, no statistical differences were found during the first 3 days after birth. However, at 7 and 10 days of age, calves showed significantly $(p<0.05)$ lower IGF-I plasma levels as compared to donkeys, while at 14 days calves showed significantly $(\mathrm{p}<0.05)$ lower levels in comparison to both horse and donkey foals (Table 3). No differences were found along the entire time of observation between horse and donkey foals.

\section{Discussion}

In humans, the IGF-I activity during prenatal growth and development represents the basis for a healthy infancy, childhood and adulthood [12]. Fetal growth is strictly related to the delivery of nutrients through the placenta, which regulates IGF-I fetal concentrations; with the disruption of the feto-maternal placental interface at birth, in human babies a decrease of postnatal IGF-I plasma levels can be observed, probably due to a low endogenous production. However, at term infants rapidly restore IGF-I plasma levels [38].

In terms, human neonates, the IGF-I decline can be usually observed at 1 day of age; then, IGF-I levels remain low until day 3, while an increasing trend can be found between day 4 and 7 [38]. During postnatal development, IGF-I concentrations are consistently high, due to its key role for growth regulation [14].

In the present study, in newborn horse foals, despite an apparent increasing trend of IGF-I plasma concentrations, an almost steady state can be observed during the first week of age. Although not significantly detectable, a weak decrease seems to occur at 24 hours of age. This decrease could resemble the postnatal decline described by Giudice et al. [38] in human babies at 1 day of age. Significant IGF-I plasma concentrations increase was found at 10 and 14 days of age in comparison to the levels recorded at 24 hours after birth. The results of the present study confirm those obtained by Panzani et al. [3], in which spontaneous healthy foals showed an increasing IGF-I plasma levels profile characterized by higher values at 14 days of age, when compared to the first week after birth; an earlier study, instead, reported a significant increase starting at 4 days of age as compared to IGF-I plasma values detected at birth [22].

Even if with slight differences on the exact time in which the IGF-I plasma levels start to increase significantly, it is possible to suggest that few days after birth a general increment of IGF-I plasma concentrations can be observed also in newborn horse foals, as reported in human babies. However, this increase could be partially explained by the assumption of these growth factors from the mare colostrum and milk, since milk IGF-I levels in the mare were reported to gradually decrease after parturition [39]. Probably, similarly to humans [11,40], during the horse foals neonatal life, most of the plasmatic IGF-I derives from the liver of the equine neonate itself, under the influence of several nutritional factors and which maintains high IGF-I plasma levels, not only for the first weeks of life, but also for the first months, when a very rapid growth of the young horse is required $[39,41,42]$. 


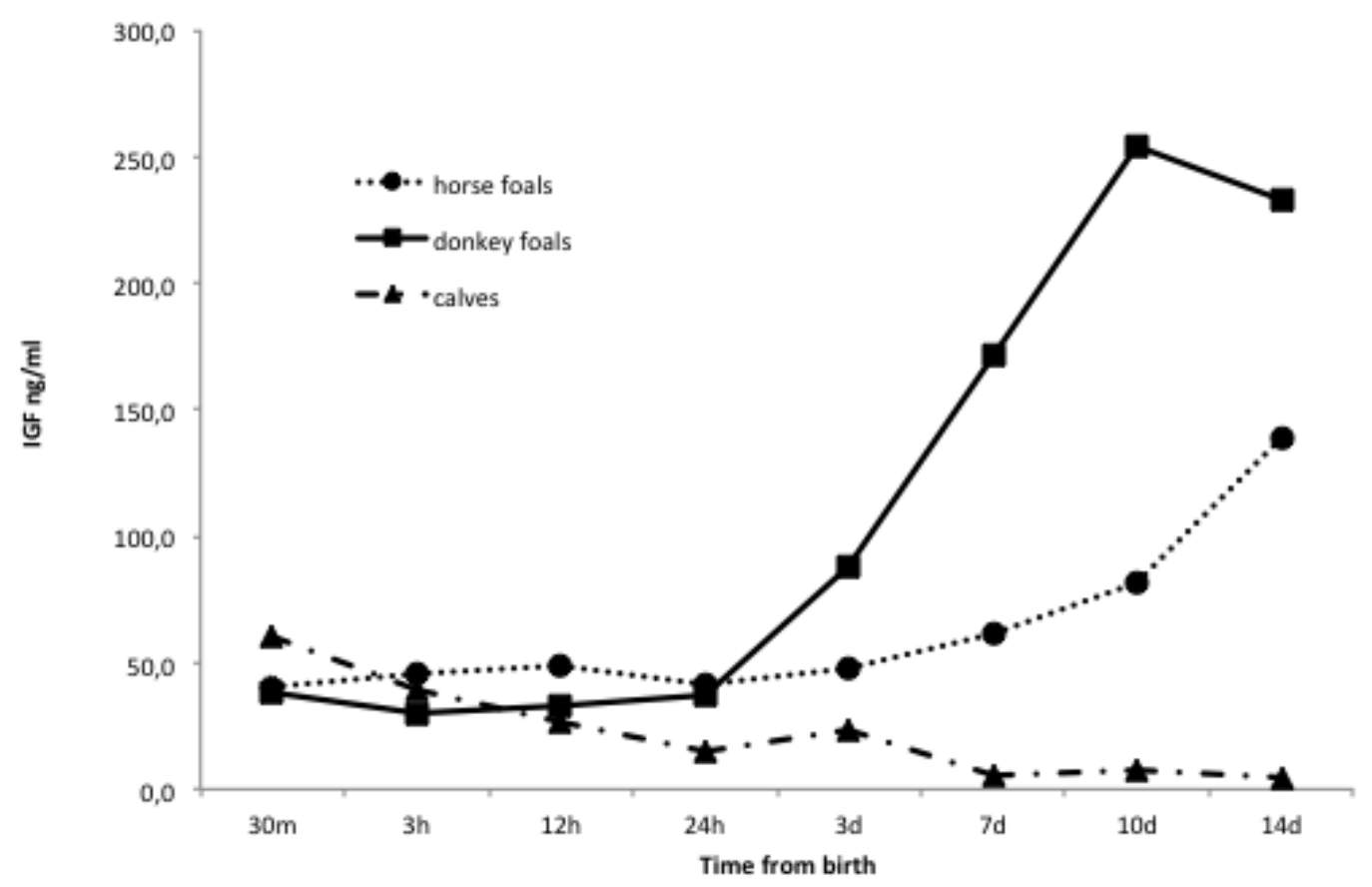

Figure 1. Mean IGF-I plasma concentrations profiles in the 6 horse foals, 6 donkey foals and 6 calves, during the first 2 weeks of age

In the present study, an apparent increasing trend has been observed also in donkey foals, which showed a peak of IGF-I plasma levels at 10 days of age. This result is partially in agreement with previous findings reported by Montillo et al.[21] and Peric et al. [20]. In those studies, the increment started at day 7 and continued until day 14 (last day of observation). To the authors knowledge, no other studies have been performed in the newborn donkey, so that further comparisons can be done only with horse foals, which, as previously discussed, showed a similar profile. In fact, in the present study, no significant differences were found between the two species during the whole period of observation. This is in contrast with the results reported by Peric et al. [20], who found higher mean plasma IGF-I levels in horses as compared to donkeys, during the first week of age. In the present study, even if no statistical differences were found, the mean IGF-I plasma levels in donkeys were always higher in comparison to that of foals. Probably, the very high individual variation between subjects, observed above all in the group of donkey foals, did not allow evidencing any statistical difference between the two groups. These results, however, suggest that, also in newborn donkey foals, the IGF-I could play an important role during the first rapid growth phase, even if further studies on larger groups of animals are needed to assess whether or not some differences may exist concerning the amount of IGF-I production between donkey and horse foals.

Looking at the results obtained in calves, an opposite IGF-I plasma profile can be observed. In fact, calves seem to have the highest IGF-I levels at birth (before colostrum intake), while a significant decrease could be found already at 3 hours of life. No increases were then observed, but, on the contrary, a further decrease at 7 days of age was detected. This completely different profile, as compared to horse and donkey foals, however, is not surprising. In fact a similar trend was previously observed by Probo et al. [19], who reported a significant decrease at day 6 of age as compared to the first 30 minutes after birth. Those authors supposed that the high initial concentrations could be the result of both maternal and/or fetal production. However, also in that study an explanation about the IGF-I plasma levels constant decline soon after birth was not hypothesised.

Insulin-like growth factor I is present in very high concentration in the first colostrum and in cow milk, indicating that they are important for growth and maturation of the calf, and especially for growth and maturation of GIT $[43,44]$. Hammon and Blum [43] reported that calves fed 6 times colostrum compared to those who received colostrum only once, or fed only milk replacer, showed higher IGF-I levels; however, the authors supposed that those high concentrations were probably due to enhanced endogenous production and not by the absorption of colostral IGF-I. In fact, contrary to other proteins and peptides, IGF-I is absorbed only in trace amounts by newborn calves; moreover, cow colostrum contains also several IGF-I binding proteins, who could be responsible for the little amount of IGF-I absorbed by the calf [43]. This implies that most of circulating IGF-I, in calves, derives from endogenous sources. However, the production of endogenous IGF-I and its regulation during the postnatal life, depends by the development stage, and require a certain degree of maturation [43]. In neonatal calves just a few number of hepatic $\mathrm{GH}$ receptors, responsible for IGF-I production, have been identified.

Despite differences among calves that received diverse types of feeding, Hammon and Blum [43] found a decreasing trend of IGF-I levels during the first week of age [43]. A decreasing trend of IGF-I mRNA levels in different calves GIT tracts has also been observed by Flaga et al. [45], who analysed the period lasting between 5 and 26 days of age. Moreover, they found that IGF-I transcript levels in the liver were the lowest during the first 26 days of life in comparison to all other examined tissues; this result suggest that in neonatal calves the liver could be not mature enough to sustain its biological functions, and colostral and milk support, together with local tissue gene expression, play the most important role in controlling GIT maturation [45]. Thus, the decreasing trend of plasma IGF-I levels observed in the present study, could be explained as a combination of different factors: high 
colostral and milk levels (demonstrated by the higher levels found during the first 24 hours compared to later samples), followed by a decreased absorption and a still low liver production. However, the highest IGF-I concentrations observed at 30 minutes after birth and before the first colostrum assumption, seem to suggest that this first "boost" of IGF-I levels could be of maternal origin.

When compared to horse and donkeys, consequently, calves showed a decrease of IGF-I plasma levels starting from 7 days of age and continuing until day 14, opposite to horse and donkey foals. This finding could therefore suggest a great difference of the role played by IGF-I in the early stage of neonatal growth and maturation between equids and cattle's. A tempting explanation of this difference could be addressed to a possible greater (or sooner) maturity of the equine liver, and a consequent higher endogenous production of IGF-I, in comparison to calves. Otherwise, a possible different physiological pathway for IGF-I production or activity, in the bovines, could be supposed.

In conclusion, this study supports the important role played by IGF-I during the early neonatal life in horse, donkey and cattle; however, several species-specific differences about IGF-I plasma concentrations profile during the first two weeks of age exist, suggesting possible different source of IGF-I production, physiological pathways and roles among neonates of different species, and possibly reflecting also differences in the times and manner of the neonatal maturation process. Once again horse and donkey showed some slight differences between each other, underlying the need of species-specific researches for a proper study of the biological features of these equines species.

\section{References}

1. Panzani S, Villani M, McGladdery A, Magri M, Kindahl H, et al. (2009) Concentrations of 15-ketodihydro-PGF2alpha, cortisol, and progesterone in the plasma of healthy and pathologic newborn foals.Theriogenology 72: 1032-1040. [Crossref]

2. Barsnick RJ, Toribio RE (2011) Endocrinology of the equine neonate energy metabolism in health and critical illness. Vet Clin North Am Equine Pract 27: 49-58.[Crossref]

3. Panzani S, Comin A, Galeati G, Romano G, Villani M, et al. (2012) How type of parturition and health status influence hormonal and metabolic profiles in newborn foals. Theriogenology 77: 67-77. [Crossref]

4. Toribio RE (2011) Endocrine dysregulation in critically ill foals and horses. Vet Clin North Am Equine Pract27: 35-47.[Crossref]

5. de Moura EG, Passos MC (2005) Neonatal programming of body weight regulation and energetic metabolism. Biosci Rep 25: 251-269.[Crossref]

6. Mullis PE (2005) Genetic control of growth. Eur J Endocrinol 152: 11-31.[Crossref]

7. Atabek ME, Pirgon O, Yorulmaz A, Kurtoglu S (2006) The role of cord blood IGF-I levels in preterm osteopenia. J Pediatr Endocrinol Metab 19: 253-257.[Crossref]

8. Ahmad I, Zaldivar F, Iwanaga K, Koeppel R, Grochow D, et al. (2007) Inflammatory and growth mediators in growing preterm infants. J Pediatr Endocrinol Metab 20: 387 396.[Crossref]

9. Hansen-Pupp I, Hellström-Westas L, Cilio CM, Andersson S, Fellman V, et al. (2007) Inflammation at birth and the insulin-like growth factor system in very preterm infants. Acta Paediatr 96: 830-836.[Crossref]

10. De Graaf-Roelfsema E, Back W, Keizer HA, Stout TZ, van der Kolk JH (2009) Normal function of the hypothalamic-pituitary growth axis in three dwarf Freisan foals. Vet Rec165: 373-6. [Crossref]

11. Ohkawa N, Shoji H, Kitamura T, Suganuma H, Yoshikawa N, et al. (2010) IGF-I, leptin and active ghrelin levels in very low birth weight infants during the first 8 weeks of life. Acta Paediatr 99 : 37-41.

12. Randhawa R, Cohen P (2005) The role of the insulin-like growth factor system in prenatal growth. Mol Genet Metab 86: 84-90.[Crossref]

13. Butler AA, LeRoith D (2001) Minireview: tissue-specific versus generalized gene targeting of the IGF1 and IGF1R genes and their roles in insulin-like growth factor physiology. Endocrinology 142: 1685-1688.
14. Monzavi R, Cohen P (2002) IGFs and IGFBPs: role in health and disease. Best Pract Res Clin Endocrinol Metab16: 433-447.[Crossref]

15. Bonefeld K, Møller S (2011) Insulin-like growth factor-I and the liver. Liver Int 31: 911-919.[Crossref]

16. Odle J, Zijlstra RT, Donovan SM (1996) Intestinal effects of milkborne growth factors in neonates of agricultural importance. J Anim Sci 74: 2509-2522.[Crossref]

17. MacDonald RS (1999) The role of insulin-like growth factors in small intestinal cell growth and development. Horm Metab Res 31: 103-113.[Crossref]

18. Jehle PM, Fussgaenger RD, Blum WF, Angelus NK, Hoeflich A, et al. (1999) Differential autocrine regulation of intestinal epithelial cell proliferation and differentiation by insulin-like growth factor (IGF) system component. Horm Metab Res 31: 97-102. [Crossref]

19. Probo M, Comin A, Faustini M, Prandi A, Veronesi MC (2010) Insuline-like Growth Factor I and Non Esterified Fatty Acids plasma concentrations in the newborn calf. Proceedings of the $14^{\circ}$ Annual Conference of the European Society of Animal Reproduction (ESDAR), Reprod Dom Anim Suppl 45: 70

20. Peric T, Panzani S, De Amicis I, Comin A, Montillo M, et al. (2012) Insulin-like growth factor I plasma concentrations in newborn healthy donkey and horse foals. Proceedings of the 16th Annual Conference of the European Society for Domestic Animal Reproduction (ESDAR) Reprod Dom Anim Suppl 47: 103.

21. Montillo M, Sergiacomo M, Contri A, Gloria A, Peric T, et al. (2013) IGF-I, NEFA and cortisol plasma concentrations in newborn donkey foals. Proceedings of the 17th Annual Conference of the European Society for Domestic Animal Reproduction (ESDAR) Reprod Dom Anim Suppl 48: 97.

22. Panzani S, Castagnetti C, Prandi A, Faustini M, Zamboni A, et al. (2013) Insulin-like growth factor I: could it be a marker of prematurity in the foal? Theriogenology 79 : 495-501.[Crossref]

23. Koterba AM, Drummond WH, Kosch P (1985) Intensive care of the neonatal foal. Vet Clin North Am Equine Pract 1: 3-34.[Crossref]

24. Carluccio A, De Amicis I, Panzani S, Tosi U, Faustini M, et al. (2008) Electrolytes changes in mammary secretions before foaling in jennies. Reprod Domest Anim 43 162-165.[Crossref]

25. Veronesi MC, Panzani S, Govoni N, Kindahl H, Galeati G, et al. (2011) Peripartal plasma concentrations of 15-ketodihydro-PGF2a, cortisol, progesterone and 17-ß-estradiol in Martina Franca jennies. Theriogenology 75: 752-759.

26. Panzani S, Carluccio A, Probo M, Faustini M, Kindahl H, et al. (2012) Comparative study on 15-ketodihydro-PGF(2 $\mathrm{I} \pm$ ) plasma concentrations in newborn horses, donkeys and calves. Reprod Domest Anim47: 82-86.[Crossref]

27. Veronesi MC, Gloria A, Panzani S, Sfirro MP, Carluccio A, et al. (2014) Blood analysis in newborn donkeys: hematology, biochemistry, and blood gases analysis. Theriogenology 82: 294-303. [Crossref]

28. Georgiev IP, Georgieva TM, Pfaffl M, Hammon HM, Blum JW (2003) Insulinlike growth factor and insulin receptors in intestinal mucosa of neonatal calves. $J$ Endocrinol 176: 121-132.[Crossref]

29. Guilloteau P, Huërou-Luron IL, Chayvialle JA, Toullec R, Zabielski R, et al. (1997) Gut regulatory peptides in young cattle and sheep. Zentralbl Veterinarmed A 44: 1-23. [Crossref]

30. Jeffcott LB (1972) Observations on parturition on parturition in crossbred pony mares. Equine Vet J4: 209-14

31. Campitelli S, Carenzi C, Verga M (1982) Factors which influence parturition in the mare and development of the foal. Appl Amim Ethol9:7-14.

32. Koterba AM, Drummond WH, Kosch PC (1990) Equine clinical neonatology. Lea \& Febiger, Philadelphia: 71-86.

33. Rossdale PD, Ousey JC, Silver M, Fowden A (1984) Studies on equine prematurity 6 Guidelines for assessment of foal maturity. Equine Vet $J$ 16: 300-302.[Crossref]

34. Schuijt G, Taverne MA (1994) The interval between birth and sternal recumbency as an objective measure of the vitality of newborn calves. Vet Rec 135: 111-115.[Crossref]

35. Karapinar T, Dabak M (2008) Treatment of premature calves with clinically diagnosed respiratory distress syndrome. J Vet Intern Med 22: 462-466.[Crossref]

36. Renaville R, Devolder A, Massart S, Sneyers M, Burny A, et al. (1993) Changes in the hypophysial-gonadal axis during the onset of puberty in young bulls. J Reprod Fertil 99: 443-449.[Crossref] 
37. Hansen-Pupp I, Löfqvist C, Polberger S, Niklasson A, Fellman V, et al. (2011) Influence of insulin-like growth factor I and nutrition during phases of postnatal growth in very preterm infants. Pediatr Res69: 448-453.

38. Giudice LC, de Zegher F, Gargosky SE, Dsupin BA, de las Fuentes L, et al. (1995) Insulin-like growth factors and their binding proteins in the term and preterm human fetus and neonate with normal and extremes of intrauterine growth. J Clin Endocrinol Metab 80: 1548-1555.[Crossref]

39. Berg EL, MnNamara DL, Keisler DH (2007) Endocrine profiles of peri-parturient mares and their foals. J Anim Sci85:1 660-668.

40. Holt RI (2002) Fetal programming of the growth hormone-insulin-like growth factor axis. Trends Endocrinol Metab13: 392-397.[Crossref]

41. Hess-Dudan F, Vacher PY, Bruckmaier RM, Weushaupt MA, Burger D, et al. (1994) Immunoreactive insulin-like growth factor I and insulin in blood plasma and milk of mares and in blood plasma of foals. Equine Vet J26: 134-139.
42. Cymbaluk NF, Laarveld B (1996) The ontogeny of serum insulin-like growth factor-I concentration in foals: effects of dam parity, diet, and age at weaning. Domest Anim Endocrinol 13: 197-209.[Crossref]

43. Hammon H, Blum JW (1997) The somatotropic axis in neonatal calves can be modulated by nutrition, growth hormone, and Long-R3-IGF-I. Am J Physiol 273: E130-138.[Crossref]

44. Hammon HM, Blum JW (2002) Feeding different amounts of colostrum or only milk replacer modify receptors of intestinal insulin-like growth factors and insulin in neonatal calves. Domest Anim Endocrinol 22: 155-168.[Crossref]

45. Flaga J, Górka P, Kowalski ZM, Kaczor U, Pietrzak P, et al. (2011) Insulin-like growth factors 1 and 2 (IGF-1 and IGF-2) mRNA levels in relation to the gastrointestinal tract (GIT) development in newborn calves. Pol J Vet Sci14: 605-613.

Copyright: $@ 2017$ Panzani S. This is an open-access article distributed under the terms of the Creative Commons Attribution License, which permits unrestricted use, distribution, and reproduction in any medium, provided the original author and source are credited. 